〔Med. Entomol. Zool. Vol. 54 No. 3 p. 267-274 2003]

\title{
Distribution and seasonal prevalence of Anopheles minimus Theobald (Diptera: Culicidae) in the Yaeyama Island group (except Ishigaki Island), Ryukyu Archipelago, Japan, 1999-2000
}

\author{
Takako Toma ${ }^{1,2)}$, Ichiro Miyagi ${ }^{1}$, Hidechika Murakami ${ }^{3)}$, Hitoshi Nerome ${ }^{3)}$, \\ Masato Yonamine ${ }^{3)}$, Yukiko Higa ${ }^{1)}$ and Yuko Tokuyama ${ }^{1)}$ \\ 1) Laboratory of Medical Zoology, School of Health Science, Faculty of Medicine, \\ University of the Ryukyus, Nishihara, Okinawa, 903-0215 Japan \\ 2) Center for Asia-Pacific Island Studies, University of the Ryukyus, \\ Senbaru 1, Nishihara, Okinawa, 903-0213 Japan \\ 3) Yaeyama Health Center of Okinawa Prefecture, Ishigaki, Okinawa, 907-0002 Japan
}

(Received: 18 December 2002; Accepted: 16 May 2003)

\begin{abstract}
In order to know the distribution and seasonal appearance of Anopheles minimus Theobald in the Yaeyama Island group, except Ishigaki Island, a comprehensive larval survey was carried out in Iriomote, Kohama, Hateruma and Yonaguni Islands from 1999 to 2000. Immatures of An. minimus were found in 4 out of 20 habitats examined in Iriomote Island, and 6 out of 13 habitats including streams, springs and ground pools near the springs examined, in Kohama Island. The abundance of the immatures in Hora Stream of Iriomote Island, and a spring of Kohama Island, showed seasonal variation which was positively correlated with water temperature. The immature was not collected during winter season (December to February) in Hora Stream. The density was high in August and October 1999 and June 2000, being 169, 151 and 111 larvae/100 dips, respectively. In the spring of Kohama, the density was 268 in August 1999, and 516 in June 2000. This is the first record of $A n$. minimus for Kohama Island. The immature was not found in Hateruma and Yonaguni Islands.
\end{abstract}

Key words: Anopheles minimus, distribution, Iriomote Island, Kohama Island, Ryukyu Archipelago, seasonal prevalence

\section{INTRODUCTION}

Until 1962, the Yaeyama Island group including Ishigaki, Iriomote, and Yonaguni Islands, and the Miyako Island group of the Ryukyu Archipelago were endemic for malaria. The disease was eradicated in the Island groups after initiation of an eradication program focusing on, among others, the control of vector mosquitoes using DDT (Farid et al., 1966). Population of the principal vector, Anopheles minimus Theobald, increased in Ishigaki Island after stoppage of the extensive use of DDT but malaria remained eradicated (Miyagi et al., 1996). A more detailed study on the distribution and seasonal occurrence of An. minimus was carried out in Ishigaki Island during 1998-1999 (Toma et al., 2002). The immatures were found in almost all the surveyed streams except those in urban areas, fast-flowing streams and polluted streams.

Miyako Island is known as the northernmost distribution of An. minimus. As the soils of Miyako Island are very loose and rain water can seep easily underground, water accumulates naturally in the underground aquifer. Before construction of an underground dam in 1979, the water emerged as springs at different sites 
within the sugar cane fields and the immatures were found in the streams originated from the water emerged from underground. Toma et al. (1996b) studied the abundance and distribution of the species in Miyako Island, and reported that the population decreased with the rapid reduction of streams after construction of the underground dam.

The survey of $A n$. minimus in the other inhabited islands of the Yaeyama Island group, Iriomote, Hatoma, Kuro, Aragusuku, Hateruma, Yonaguni, Kohama and Taketomi was carried out fragmentarily after the malaria eradication (Sasa et al., 1977; Miyagi and Toma, 1978; Miyagi et al., 1983; Tanaka et al., 1979). During the endemic time, malaria cases were reported in the small islands of the Yaeyama Island group, although there was no $A n$. minimus. It was also reported that residents in the Islands were infected with malaria, when they visited the endemic areas, Ishigaki and Iriomote Islands, for agricultural activities (Yoshino, 1956) and compulsory evacuation during World War II (Kuroshima, 1960; Miyara, 1990; Sakihara et al., 1994). Recent increased interest in the geographical distribution of vector mosquitoes has resulted from the global warming with dispersal of the sibling species of An. minimus in the Ryukyu Archipelago. Somboon et al. (2001) reported that An. minimus from Ishigaki Island was a new sibling species (E), being different from those of Thailand. In order to know the distribution and seasonal prevalence of An. minimus in the Yaeyama Island group (except Ishigaki Island), a comprehensive survey was carried out in Iriomote, Kohama, Hateruma and Yonaguni Islands from 1999 to 2000.

\section{Materials and Methods}

\section{Study area}

Iriomote Island is located approximately $450 \mathrm{~km}$ south of Okinawa Island, and 31 $\mathrm{km}$ west of Ishigaki Island (Fig. 1). It has an area of $284.4 \mathrm{~km}^{2}$, with a population of

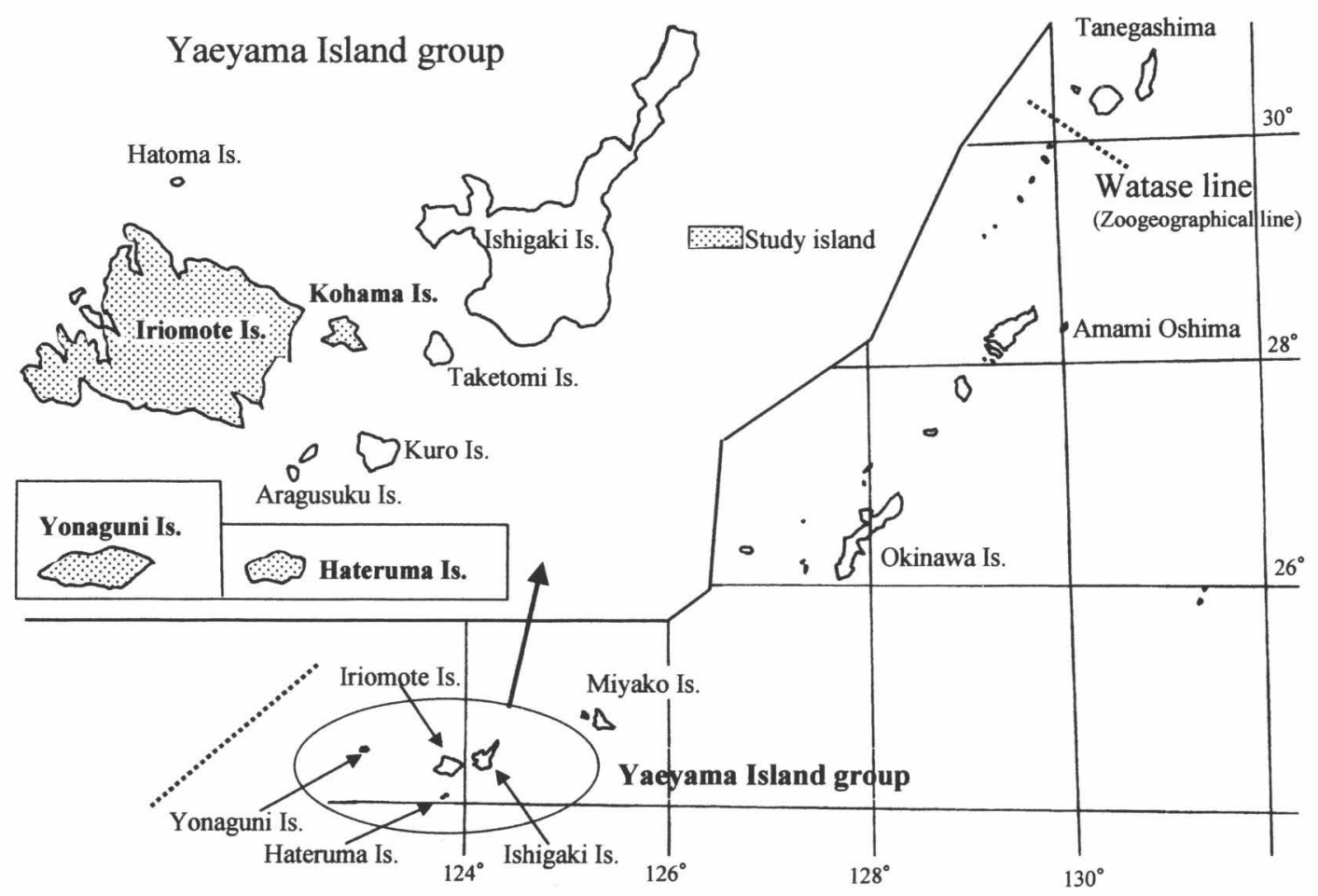

Fig. 1. Map of the Ryukyu Archipelago, and study islands. 
about 2,000. The island is covered thickly by trees, and inhabitants live only in the peripheral area. Kohama Island (area, 8.1 $\mathrm{km}^{2}$; population, 470) is located between Ishigaki and Iriomote Islands. Hateruma Island (area, $12.5 \mathrm{~km}^{2}$; population, 560) is $56 \mathrm{~km}$ southwest of Ishigaki Island. Yonaguni Island (area, $28.5 \mathrm{~km}^{2}$; population, 1,840 ) is located $127 \mathrm{~km}$ southwest of Ishigaki Island.

\section{Survey procedure}

To know the distribution of $A n$. minimus larvae and the seasonal abundance of the immatures in each island, streams with permanent flowing water were selected by using a $1: 50,000$ scale map, for the survey. In Iriomote Island, collections were made in 20 streams on May 20-22, 1999 (Fig. 2). In Kohama, Hateruma and Yonaguni Islands, efforts were made to search for streams, springs and swamps originated from springs suitable for $A n$. minimus breeding. Larvae were collected in 5 springs, and 1 stream, 2 ditches, 1 paddy field, 2 ground pools, and 1 swamp, with water originated from the springs, in Kohama Island on March 4-6, 1999. In Hateruma Island, a reservoir for keeping spring water and a ditch connected with a spring and 8 other habitats were examined on June 9 and September 6, 1999. In Yonaguni Island, collections were carried out in 4 springs and 6 ground spring water pools on June 10-11 and September 7-8, 1999. Collections were made by using a dipper (approximately $500 \mathrm{~m} l$ volume) and a small net fastened on a wire frame $(8 \times 10.5 \mathrm{~cm})$. At each site, 100 dips were made by two trained persons.

In addition, two streams each in Iriomote and Kohama Islands were selected to study the seasonal appearances of the immatures from August 1999 to June 2000. The sites were Hora Stream (No. 12 in Fig. 2) and Haemi Spring (No. 20 in Fig.

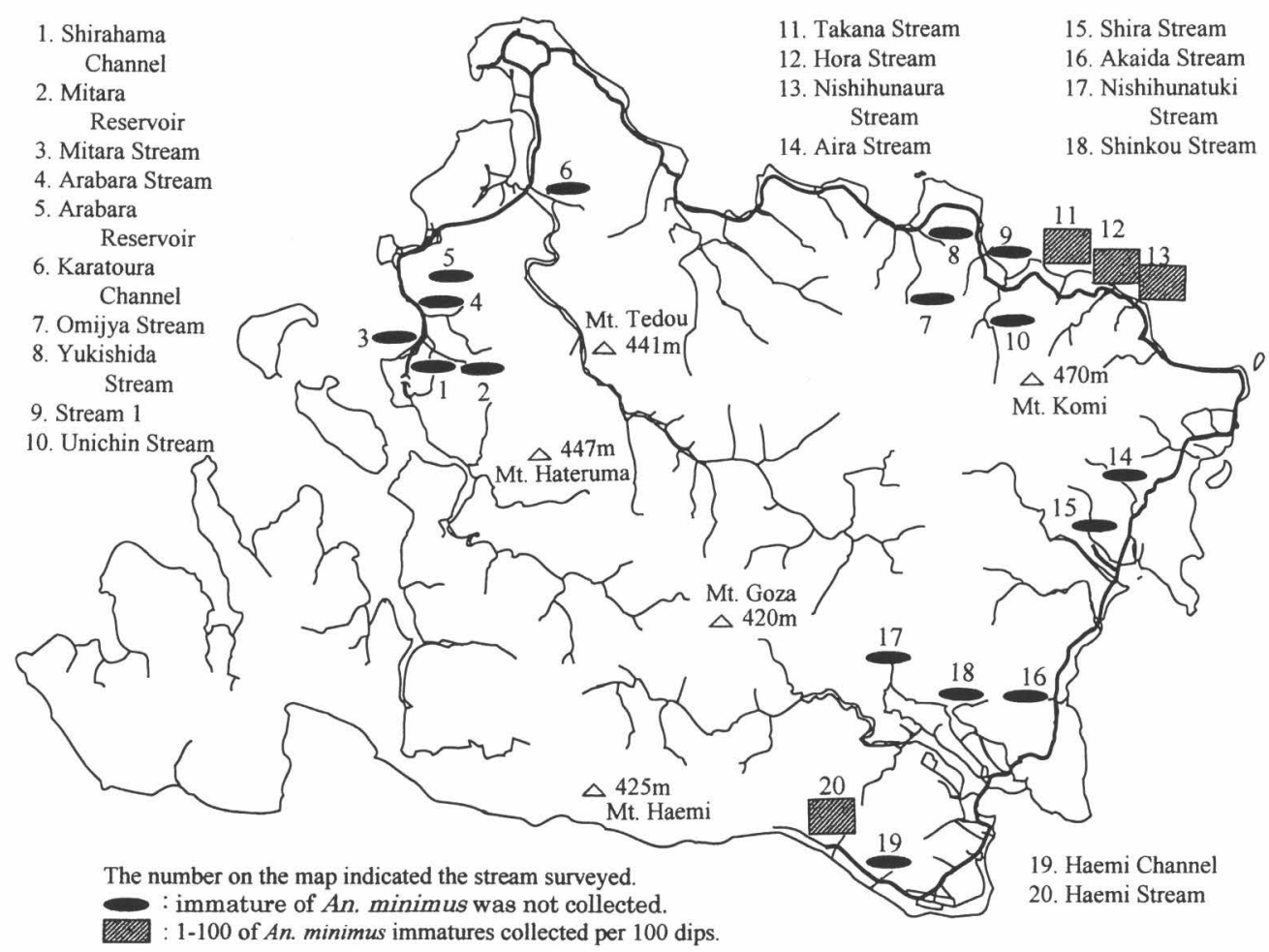

Fig. 2. Distribution and density of Anopheles minimus in 20 habitats of Iriomote Island, Ryukyu Archipelago, 1999. 
2) in Iriomote Island, and two springs (No. 1 and 3, localities were not shown) in Kohama Island. Spring No. 1 of Kohama Island was situated east of a village at the center of the island, and near the backyard of a sugarcane factory. Spring No. 3 was situated south of the village. The immatures were collected every two months from August 1999 to June 2000 by the above-mentioned method.

Weather records on rainfall and ambient temperature were obtained from the Okinawan Meteorological Bureau. Water temperature was measured and recorded at each site during the survey on seasonal prevalence.

\section{Results AND Discussion}

\section{Iriomote Island}

Figure 3 shows changes in the average air temperature and total rainfall from April 1999 to June 2000 in Ohara, Iriomote Island. The lowest air temperature $\left(18.3^{\circ} \mathrm{C}\right)$ was recorded in February 2000, while the highest $\left(28.6^{\circ} \mathrm{C}\right)$ was in July and August 1999 and June 2000. Peak rainfall (308 mm) was recorded in September 1999. The annual rainfall of the Island $(2,268 \mathrm{~mm})$ was higher than that of Ishi- gaki Island $(2,148 \mathrm{~mm})$, while the average temperature $\left(23.7^{\circ} \mathrm{C}\right)$ of each month was a little lower than that of Ishigaki Island $\left(24.3^{\circ} \mathrm{C}\right)$.

Anopheles minimus immatures were found in 4 out of 20 streams in Iriomote Island (Fig. 2). The infestation rate was $20 \%$ and the number of the immatures collected was small, being $1-100$. The infestation rate of Iriomote Island was lower than those of Ishigaki Island which was $69 \%$ and $68 \%$ in 1998 and 1999, respectively (Toma et al., 2002). In the mosquito surveys of Ishigaki and Iriomote Islands from 1938 to 1942 , the infestation rate of An. minimus was nearly $100 \%$ in the malaria endemic area that was almost the entire area, except a business part, of Ishigaki Island, and $62.5 \%$ in the malaria endemic area that was all of Iriomote Island. The ratio of $A n$. minimus to all mosquitoes collected was also lower in Iriomote Island compared to Ishigaki Island (Yoshino, 1956). The results of the present survey were almost the same as those of Yoshino (1956).

Figure 4 shows the water temperature and the number of the immatures collected in Iriomote Island. In Haemi Stream (No. 20 in Fig. 2) (Fig. 4a), the temperature

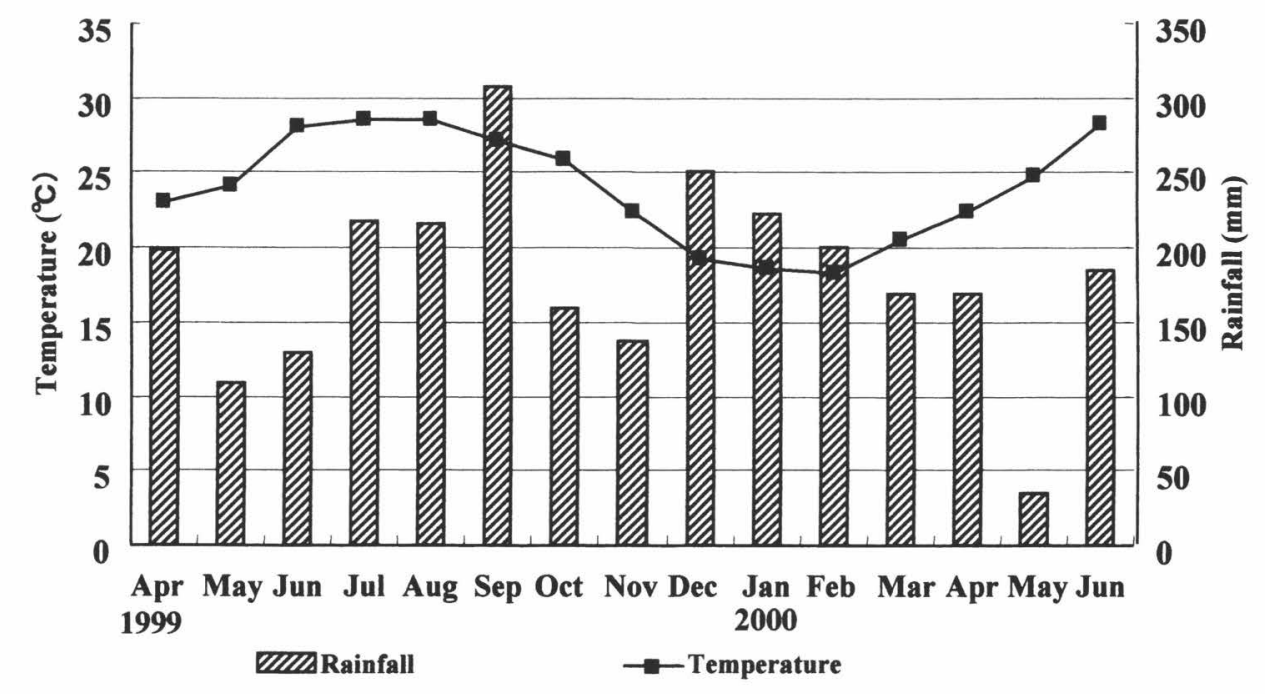

Fig. 3. Changes in average temperature and rainfall from April 1999 to June 2000 in Iriomote Island, Ryukyu Archipelago. 

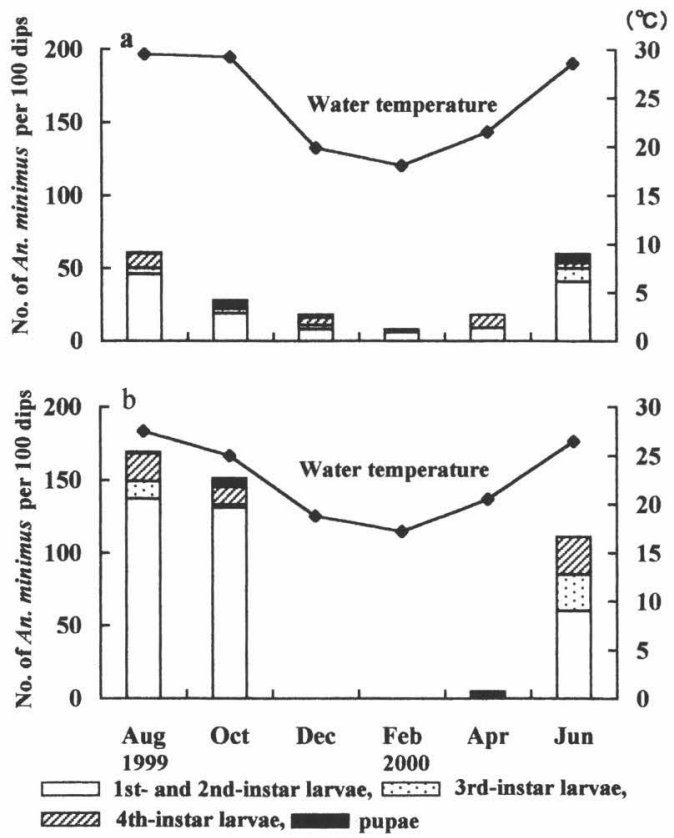

Fig. 4. Seasonal prevalence of Anopheles minimus immatures in Haemi Stream (a, No. 20) and Hora Stream (b, No. 12) of Iriomote Island, Ryukyu Archipelago.

was low in December to February (18.1$19.9^{\circ} \mathrm{C}$ ), and high in August and October 1999 , and in June $2000\left(28.6-29.5^{\circ} \mathrm{C}\right)$. The number of the immatures was low (8) in February 2000, and high (61) in August 1999 and June 2000. In Hora Stream (No. 12 in Fig. 2) (Fig. 4b), the temperatures in December 1999 and February 2000 were lower $\left(17.2-18.8^{\circ} \mathrm{C}\right)$ than those of Haemi Stream, and the immatures were not collected in these months. The temperatures in August $1999\left(27.5^{\circ} \mathrm{C}\right)$ and June 2000 $\left(26.5^{\circ} \mathrm{C}\right)$ in Hora Stream, were also lower than those of Haemi Stream. The number of the immatures collected in Hora Stream was high in August and October 1999, and June 2000, being 111-169. There was a positive correlation between the seasonal temperature change and the abundance of immatures in the two streams as shown in Ishigaki Island (Toma et al., 2002). The rate of young instar larvae collected was high in August and October 1999 and June 2000 (hot months), and was low in February 2000 (cold month) in Haemi
Stream. It means that the adult activities such as blood-sucking and oviposition, are high in a hot month and low in a cold month. The pupae were collected in all months of the survey period, the number being apparently small in the cold month. From the results, the larvae developed slowly and pupated even in a cold month in Haemi Stream.

Iriomote and Ishigaki Islands are large islands among the island groups. The permanent populations in 2000 were quite different between them, 2,000 in Iriomote Island and 44,000 in Ishigaki Island. In Iriomote Island, most of the areas are covered thickly by protected forests, and paved roads are limited to the peripheral area occupied by a limited number of inhabitants and livestock. The island has several large rivers with plentiful water originated from mountain forests to the seacoast and with mangrove trees.

Ishigaki Island has a good network of roads, and bus transportation is well developed. It has many irrigation areas, livestock breeding areas in the central part, where there are many small slow-flowing streams. The immatures of $A n$. minimus prefer unpolluted and small slow-flowing streams (width, less than $6 \mathrm{~m}$ ) with sunlight filtering down through trees and shrubs (Toma et al., 1996a).

The number of streams harboring $A n$. minimus in Iriomote Island was low, compared to Ishigaki Island. Such a localized distribution of the species in the Island might be due to the small number of blood source animals, cattle, and the unsuitable condition of streams for breeding. According to the official statistics of Okinawa Prefecture in 2000, the number of livestock in Iriomote Island consisted of 2,064 cattle, 3 horses, 59 goats, and 39 water buffaloes, while Ishigaki Island had 27,131 cattle, 179 horses, 5,542 pigs, 259 goats, and 31 water buffaloes. The average number of livestock per $\mathrm{km}^{2}$ was 7.6 in Iriomote Island and 149.9 in Ishigaki Island. During the malaria endemic time, few livestock were found on both islands, 
and most of the inhabitants in the endemic areas stayed in unprotected houses and were frequently bitten by infected mosquitoes (Yoshino, 1956; Kuroshima, 1960).

\section{Kohama Island}

Of the 13 habitats surveyed in Kohama Island, 6 (4 springs, 1 ditch and 1 ground pool) had the immatures of An. minimus. The rate $(46.2 \%)$ was higher than that of Iriomote Island. The number of immatures collected was also low in March 1999, being 1-100.

In spring No. 1 of Kohama Island (Fig. $5 a)$, the temperature was the highest $\left(26^{\circ} \mathrm{C}\right)$ in October 1999 , and the lowest $\left(21.2^{\circ} \mathrm{C}\right)$ in February 2000 . The number of the immatures was low (52-77) during October 1999 to April 2000, and the highest (516) in June 2000. The rate of young instar larvae was high in August 1999 and June 2000, and was low from October to December 1999, and from February to April 2000. It means that the adult activities, blood-sucking and oviposition,

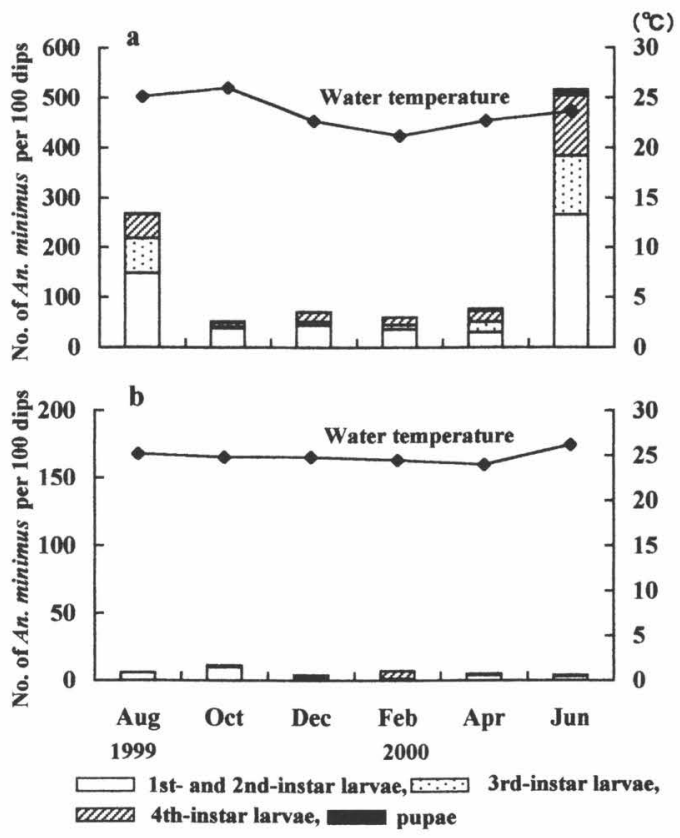

Fig. 5. Seasonal prevalence of Anopheles minimus immatures in two springs (a, No. 1 and b, No. 3) of Kohama Island, Ryukyu Archipelago. become high in August 1999 and June 2000, and become low in October to April 2000. The condition was much the same as at Haemi Stream, Iriomote Island. At spring No. 3 (Fig. 5b), the temperature during the survey was $24-26.2^{\circ} \mathrm{C}$. $\mathrm{Al}$ though it was suitable for the immature breeding, the density was low, being 4-11. The low density is probably related to the scarcity of springs and the small size of the spring, and the presence of guppy, Gambusia affinis affinis, introduced to the swamps and paddies for vector mosquito control of malaria in all areas of Yaeyama Island in 1924 for the first time. In Kohama Island, indigenous malaria cases were reported (Miyara and Nakazato, 1936; Yoshino, 1956), but the occurrence of $A n$. minimus was not reported until the present time. This is a new record of this species from this island. It might have been a principal vector of malaria in this island during the malaria endemic time. According to an old resident in the island, plenty of water gushed out, and paddies and streams were common in the island.

\section{Hateruma and Yonaguni Islands}

The survey was carried out in 10 habitats each on Hateruma and Yonaguni Islands on 2 occasions (June and September). The immature of $A n$. minimus was not collected in both Islands. The average, low and high temperatures were similar to those of Iriomote Island where An. minimus immatures were collected in this survey. There was no suitable habitat for the immatures breeding in Hateruma Island despite our extensive survey. Although mosquito surveys were carried out by Yoshino (1956) and Sasa et al. (1977) in Hateruma Island, this species was not collected in this island. During World War II, malaria patients who were infected in the endemic areas, Ishigaki and Iriomote Islands, were reported from Hateruma Island (Yoshino, 1956; Sakihara, 1994 et al.). Many malaria cases also were reported from other small islands around Ishigaki and Iriomote Islands, such as 
Hatoma, Kuro, Aragusuku, and Taketomi Islands. These might be imported cases and not indigenous cases, due to the absence of $A n$. minimus in the islands.

In Yonaguni Island, there are many streams that seem to be suitable for $A n$. minimus immatures breeding. However, immatures were not collected on the two occasions of the survey. According to Okinawan Meteorological Bureau, the average temperature was $24.2^{\circ} \mathrm{C}$ from April 1999 to June 2000. It was high in July $\left(28.6^{\circ} \mathrm{C}\right)$ and August $\left(28.4^{\circ} \mathrm{C}\right) 1999$, and low in February $2000\left(18.4^{\circ} \mathrm{C}\right)$ in Yonaguni Island. These temperatures were similar to those of Iriomote Island and Ishigaki Island where $A n$. minimus were breeding. Occurrences of both malaria cases and the vector mosquito, $A$ n. minimus, were reported during the malaria endemic period in this island. The infestation rate of the mosquitoes in the island was lower than those of Ishigaki and Iriomote Islands (Miyara and Nakazato, 1936; Yoshino, 1956). During 1977-1981, An. minimus was not collected (Miyagi et al., 1983), although surveys were carried out extensively on 5 occasions. It is not clear why this species disappears or why the density decreases drastically in the island; however, polluted water of streams due to usage of different chemicals and fertilizers for agriculture and cemented streambanks might influence $A n$. minimus breeding.

\section{ACKNOWLEDGEMENTS}

The authors wish to thank Dr. Z. Shimabukuro and Mr. Y. Asato of Yaeyama Health Center of Okinawa Prefecture, Ishigaki City and Mr. T. Kishimoto and Mr. T. Nakasone of Prefectural Institute of Health and Environment, Okinawa Prefecture, Okinawa for cooperation in the field study. The authors also wish to thank Dr. Yong Hoi Sen, Faculty of Science, University of Malaya, for reading the manuscript and for useful comments. This study was supported by Grant-in-Aid for Scientific
Research on Priority Areas (No. 1147228) from the Ministry of Education, Science, Culture and Sports, and Grant for Special Program on Promotion of Regional Health, 1998-2001, Ministry of Health and Welfare, Japan.

\section{REFERENCES}

Farid, M. A., Chen, C. T., Hsu, T. C. and Liu, S. Y. 1966. Report of WHO evaluation team on malaria eradication in the Ryukyu Islands, 1965. WPR/419/65: $1-53$.

Kuroshima, C. 1960. Results of malaria eradication in Yaeyama Island. Kankyo Eisei, 7: 18-25 (In Japanese).

Miyagi, I. and Toma, T. 1978. Studies on mosquitoes in Yaeyama Island: 1. Appearances of anopheline mosquitoes, especially Anopheles minimus minimus Theobald in Ishigakijima and Iriomotejima. Jpn. J. Sanit. Zool., 29: 243-250 (In Japanese with English summary).

Miyagi, I., Toma, T. and Iha, S. 1983. Studies on the mosquitoes in Yaeyama Islands, Japan. 8. On the mosquitoes collected in Yonagunijima. Jpn. J. Sanit. Zool., 34: 1-6 (In Japanese with English summary).

Miyagi, I., Toma, T., Malenganisho, W. L. M. and Uza, M. 1996. Historical review of mosquito control as a component of the malaria eradication program in the Ryukyu Archipelago. Southeast Asian J. Trop. Med. Public Health, 27: 139-152.

Miyara, K. 1990. My Life with Microscope: A Footprint as a Medical Technician. 241 pp. Yashima, Okinawa (In Japanese).

Miyara, T. and Nakazato, T. 1936. Notes on malaria in Yonaguni Island. Jitui, 13: 7(597)-87(604) (In Japanese).

Sakihara, S., Nishi, K., Toyama, F., Uza, M. and Taira, K. 1994. A revised analysis of malaria epidemic in Ryukyu Islands during World War II. Jpn. J. Health Hum. Ecol, 60: 67-84 (In Japanese with English summary).

Sasa, M., Kamimura, K. and Miyagi, I. 1977. Mosquitoes. In: Animals of Medical Importance in the Nansei Island in Japan (ed. Sasa, M., Takahashi, H., Kano, R. and Tanaka, H.), pp. 137-175. Shinjuku Shobo Ltd., Tokyo.

Somboon, P., Walton, C., Sharpe, R. G., Higa, Y., Tuno, N., Tsuda, Y. and Takagi, M. 2001. Evidence for a 
new sibling species of Anopheles minimus from the Ryukyu Archipelago, Japan. J. Am. Mosq. Control Assoc., 17: 98-113.

Tanaka, K., Mizusawa, K. and Saugstad, E. S. 1979. A revision of the adult and larval mosquitoes of Japan (including the Ryukyu Archipelago and the Ogasawara Islands) and Korea (Diptera: Culicidae). Contrib. Am. Entomol. Inst. (Ann Arbor), 16: 1-987.

Toma, T., Miyagi, I., Malenganisho, W. L. M., Murakami, H., Nerome, H. and Yonamine, M. 2002. Distribution and seasonal occurrence of Anopheles minimus in Ishigaki Island, Ryukyu Archipelago, Japan, 1998-1999. Med. Entomol. Zool., 53, Suppl.: 29-42.
Toma, T., Miyagi, I., Malenganisho, W. L. M., Tamashiro, M., Takagi, M., Higa, Y., Tsuda, Y., Sugiyama, A. and Ishak, H. 1996a. Distribution and seasonal prevalence of the malaria vector mosquito, Anopheles minimus in Ishigaki Island, Ryukyu Archipelago, Japan, 1990-1994. Jpn. J. Sanit. Zool., 47: 63-72. Toma, T., Miyagi, I., Takagi, M. and Tsuda, Y. 1996b. Survey of Anopheles minimus immatures in Miyako Island, Ryukyu Archipelago, Japan, 1991 and 1995. Med. Entomol. Zool., 47: 167-170.

Yoshino, K. 1956. Malaria in Yaeyama Island, southern part of the Ryukyu Archipelago. Kagoshima Igaku Zasshi, 29: 105-124 (In Japanese). 